\title{
Fouling layer on hollow-fibre membrane in aerobic granule membrane bioreactor
}

\author{
Yu-Chuan Juang ${ }^{a}$, Duu-Jong Lee ${ }^{\mathrm{a}, *}$, Juin-Yih Lai ${ }^{\mathrm{b}}$ \\ ${ }^{a}$ Department of Chemical Engineering, National Taiwan University, Taipei 10617, Taiwan \\ ${ }^{\mathrm{b}}$ Department of Chemical Engineering, R\&D Center of Membrane Technology, Chung Yuan Christian University, Chungli 32023, Taiwan
}

Received 14 August 2008; accepted 15 August 2008

\begin{abstract}
Aerobic granulation (AG) and membrane bioreactor (MBR) are two promising, novel environmental biotechnological processes that draw interest of researchers engaging work in the area of biological wastewater treatment. Membrane fouling in the combined, AGMBR process was investigated in this work. The fouling layer formed on hollow-fibre membranes in both reactors were for the first time directly observed with the multiple staining and confocal laser scanning microscope (CLSM) technique. Fouling layers in both reactors presented a rather heterogeneous fouling layer, with that on SMBR much more redundant than that on AGMBR. The EPS in the AGMBR fouling layer was principally consisted of proteins, $\alpha$-polysaccharides, and lipids, with few $\beta$-polysaccharides or cells. In SMBR, large quantity of DNA was probed in the fouling layer. Over-deposition of fouling layer on hollow-fibre membrane may assist preventing occurrence of irreversible fouling, which is beneficial to longterm operation of the AGMBR.
\end{abstract}

(C) 2008 Taiwan Institute of Chemical Engineers. Published by Elsevier B.V. All rights reserved.

Keywords: Membrane bioreactor; Hollow-fibre membrane; Aerobic granule; Fouling; CLSM

\section{Introduction}

Aerobic granules are considered to be a special case of biofilm composing of self-immobilized cells. The first patent was granted by Heijnen and Loosdrecht van (1998). de Kreuk et al. (2007) and Adav et al. (2008a) provided comments on state of the art for the aerobic granulation process. Compact structured, biologically efficient aerobic sludge granules with wide diverse microbial species and excellent settling capabilities have been developed in sequencing batch reactors (SBRs) (Adav et al., 2007b; Beun et al., 1999; Liu and Tay, 2004; Tay et al., 2001; Yang et al., 2003). Because of the unique granule attributes, the aerobic granulation technology has recently been developed for treating high-strength wastewaters containing organics, nitrogen, phosphorus, toxic substances and xenobiotics (Adav et al., 2007a,b,c,d,e, 2008b; Adav and Lee, 2007, 2008a,b; Jiang et al., 2002; Lin et al., 2003; Moy et al., 2002).

Smith et al. (1969) first reported on the combined use of membranes in biological wastewater treatment. The main

\footnotetext{
* Corresponding author. Tel.: +886 2 2362532; fax: +886 223623040 .

E-mail address: djlee@ntu.edu.tw (D.-J. Lee).
}

advantage of using membrane bioreactor (MBR) technology over using other conventional biological processes is to produce quality water from municipal wastewater for reuse, meeting the need for saving water, particularly in regions of water shortage. Yamamoto et al. (1989) developed the first submerged type MBR that are in wide use today. Membrane fouling results in flux decline and fouling increases pressure drop across the membrane (Chen et al., 2008). Sridang et al. (2005) analyzed the fouling potential of a membrane utilizing different module configurations and hydrodynamic environments. Seo et al. (2005) determined that the hydrophobic fraction of organic compounds fouled the membrane more than did hydrophilic fraction. Jarusutthirak et al. (2002) indicate that polysaccharide colloids accounted for most fouling of UF and NF membranes. Cho et al. (1999) argued that polysaccharides and related substances are the principal foulants of UF and NF membranes. Rosenberger et al. (2005) indicated the impact of soluble or colloidal fractions in organic substances, particularly polysaccharides, on membrane fouling, and thereby arguing for characterizing liquid-phase compositions when monitoring membrane process performance. Ramesh et al. (2006, 2007) revealed the potentials of individual components in EPS to foul the MBR membrane. 
Recent development in aerobic biogranulation technology is reviewed and presented in this paper. Factors affecting granulation, granule characterization, granulation hypotheses, effects of different operational parameters on aerobic granulation, response of aerobic granules to different environmental conditions, their applications in bioremediations, and possible future trends are delineated. Applications in treating municipal and toxic industrial wastewaters as well as useful information on exploring the underlined mechanisms are also highlighted. The review aims at providing a deeper understanding on aerobic granulation using newly employed confocal laser scanning microscopic techniques and microscopic observations of granules.

Advanced wastewater treatment technologies were extensively developed (Chang et al., 2007; Chiang et al., 2007; Chu et al., 2007; Liu and Lee, 2007; Shi and Lee, 2007; Wang and Liu, 2007; Yang and Lee, 2007; Yu and Stanford, 2007). Granular bioreactors can couple with other treatment units to complement benefits from both processes. For instance, Tay et al. (2008) proposed a new process, named aerobic granular sludge membrane bioreactor (AGSBR) that combined MBR and aerobic granule technology for wastewater treatment. The system indicated excellent membrane permeability with aerobic granules in a four months operation compared with the conventional MBR, and it was claimed that low membrane fouling was induced by the high strength of the aerobic granules in surface cake. Jun et al. (2007) also noted enhanced filterability for aerobic granular membrane over conventional biofloc systems. The authors concluded that the main components for fouling are proteins and polysaccharides in water. Thanh et al. (2008) utilized a baffled membrane filtration unit as the post-treatment unit of an aerobic granular sludge process. These authors noted that the soluble polysaccharides content increases with increasing organic loadings, and contributes most of the membrane resistance during filtration of effluent from aerobic granular process. Wang et al. (2008) developed their aerobic granular sludge membrane bioreactor (GMBR), which showed good organics removal (TOC removal $>84.7 \%$ ) and simultaneous nitrification and denitrification (SND) performances for synthesized wastewater. These authors noted that the SND capacity was yielded by the aerobic granules, while the large granules were disintegrated when being transferring from SBR to GMBR system.

No study exists to the authors' best knowledge on the direct observation of the fouling layer on a hollow-fibre membrane of the AGSBR and the corresponding activated sludge system. This work provided the first observation on the so-yielded fouling layers and compared their difference on membrane fouling behavior.

\section{Experimental}

\subsection{Aerobic granular sludge}

Aerobic granules were cultivated with the procedures described by Adav et al. (2007b). Stable granules formed in three weeks. The cultivated, mature granules were washed with pure water and then stored at $8{ }^{\circ} \mathrm{C}$ for 60 days in reagent bottles containing synthetic wastewater with compositions the same as those used by Adav et al. (2007b) combined with $250 \mathrm{mg} / \mathrm{L}$ phenol and $400 \mathrm{mg} / \mathrm{L}$ peptone.

\subsection{Membrane bioreactor}

Two laboratory-scale MBRs $(800 \mathrm{~mL})$ were utilized in the present study. The membrane module was made of polyethylene hollow-fibre membranes of $500 \mu \mathrm{m}$ diameter and $0.4 \mu \mathrm{m}$ pores, provided by Mitsubishi Rayon Co. (Tokyo, Japan). The specifically prepared membrane module had a working surface of $0.03 \mathrm{~m}^{2}$. Coarse bubbles were produced below the membrane module at a flow rate of $3 \mathrm{~L} / \mathrm{min}$.

A synthetic substrate with phenol as sole carbon source was prepared with the following composition $(\mathrm{g} / \mathrm{L})$ : phenol 2.5, $\mathrm{NH}_{4} \mathrm{Cl} 1.0, \mathrm{~K}_{2} \mathrm{HPO}_{4} 8.25, \mathrm{KH}_{2} \mathrm{PO}_{4} 6.75$, and $\mathrm{MgSO}_{4} \cdot 7 \mathrm{H}_{2} \mathrm{O}$ 0.65 . The prepared substrate has the COD contribution of $3000 \mathrm{mg} \mathrm{COD} / \mathrm{L}$. The substrate was continuously fed at the bottom of the MBR at $1.2 \mathrm{~mL} / \mathrm{min}$. The effluent was drawn at an on-off mode of 15-15 min partition.

\subsection{Analytical methods}

To probe the internal structure of granules, the present work employed the confocal laser scanning microscope (CLSM, OLYMPUS BX50) equipped with an image processor (OLYMPUS FV5 PSU) and an argon laser source to stimulate the fluorescence. The granule was imaged with a $10 \times$ objective with the software FLUOVIEW version 3.0. All probes were purchased from Molecular Probes (CA, USA). SYTO $63(20 \mu \mathrm{M})$ was used to stain the nucleic acid in granule, then the stained sample was placed on the shaker table for $30 \mathrm{~min}$. FITC was used to staining the amine-reactive compounds like protein in sample. $0.1 \mathrm{M}$ sodium bicarbonate buffer was first added to sample to maintain the amine group in non-protonated form, then FITC solution $(10 \mathrm{mg} / \mathrm{mL})$ was added to incubate the sample for $1 \mathrm{~h}$ at room temperature with continuous stirring. The Concanavalin A label tetramethylrhodamine, after centrifugation to remove solids, was used to probe glycol-conjugates like $\alpha$-mannopyranosyl and $\alpha$ glucopyranosyl residues in granule. After each staining for $30 \mathrm{~min}$, the sample was washed twice to remove extra stain by phosphate buffered saline (PBS). Finally, the sample was embedded in low-melting-point agar (with melting point of $75^{\circ} \mathrm{C}$ and gelling point of $38^{\circ} \mathrm{C}$ ) for observing. The FITC probe was detected by excitation with an argon laser at $488 \mathrm{~nm}$ and a band-pass filter $(500-550 \mathrm{~nm})$. A helium-neon green laser at $543 \mathrm{~nm}$ with a band-pass filter $(550-560 \mathrm{~nm})$ was used to detect Concanavalin A conjugate. The fluorescence of SYTO 63 was detected by excitation with a helium-neon laser at $633 \mathrm{~nm}$ and a band-pass filter $(650-700 \mathrm{~nm})$.

\section{Results and discussion}

\subsection{Reactor performance}

Fig. 1 shows the changes in transmembrane pressure (TMP) for AGMBR and SMBR. The AGMBR was seeded with the 


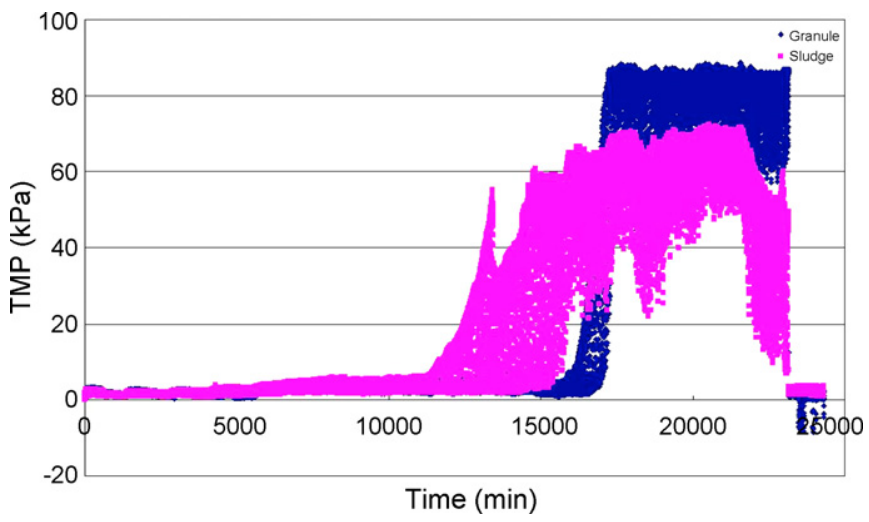

Fig. 1. Transmembrane pressure of AGMBR and SMBR as a function of testing time.

cultivated granules while the SMBR was seeded with activated sludge from a local wastewater treatment plant. The TMP was low $(<3 \mathrm{kPa})$ up to min 11,000 . What follows is an increase phase in TMP, accompanied with regular membrane backwashing. During min 11,000-15,050 the simple backwashing effectively cleaned up the membrane, yielding a complete restoration of the TMP following washing. Restated, reversible fouling was established on the hollow-fibre membrane in SMBR. However, the fouling occurred rapidly after washing, acquiring another backwashing in $20 \mathrm{~min}$ of operation. On min 16,000 and after, the physical backwashing no longer restored completely the filtration behavior with the incorporation of irreversible fouling. This occurrence is evidenced by the fact that the TMP after washing remained $>35 \mathrm{kPa}$, suggesting that certain clogged pores were not cleaned up. Up to min 22,000 the filtration flux could not be maintained and the system finally shut down on $\min 23,500$.
The TMP-time curve for AGMBR revealed a different pattern. The TMP jump was noted until >16,000 min, indicating that the foulants could not effectively clog the membrane with the presence of granules. However, once fouling occurred to some extent, irreversible fouling dominated. The backwashing could never completely restore the TMP after fouling. Bachwashing only achieved a TMP of around $60 \mathrm{kPa}$; while the period for keeping sustainable flux was only $8-10 \mathrm{~min}$, shorter than that noted for the SMBR (20 $\mathrm{min})$.

\subsection{Fouling layers}

Fig. 2 presents the fluorescent staining results of fouling layer on the central fraction of a single fibre positioned close at the central regime of the AGMBR. A cross-sectional view is noted. A rather heterogeneous fouling layer was attached on the membrane. A sticky curtain-like aggregate of thickness of 200$300 \mu \mathrm{m}$ and length of about $1.1 \mathrm{~mm}$ attached at one side of the membrane. Most of the surface presented some clusters of EPS. The EPS in the fouling layer was principally consisted of proteins, $\alpha$-polysaccharides, and lipids. Few $\beta$-polysaccharides or cells were detected in the fouling layer.

Fig. 3 presents the fluorescent staining results of fouling layer on the central fraction of a single fibre positioned close at the central regime of the SMBR. A very heterogeneous and very thick (up to $800 \mu \mathrm{m}$ ) fouling layer covered the entire membrane surface. Unlike the AGMBR, redundant cells were noticeable in the fouling layer, with the live cells sitting mainly outside and the dead cells inside the biofilm. Proteins and lipids distributed uniformly over the biofilm; while the $\alpha$-polysaccharides were detected associated with the live cells layer.

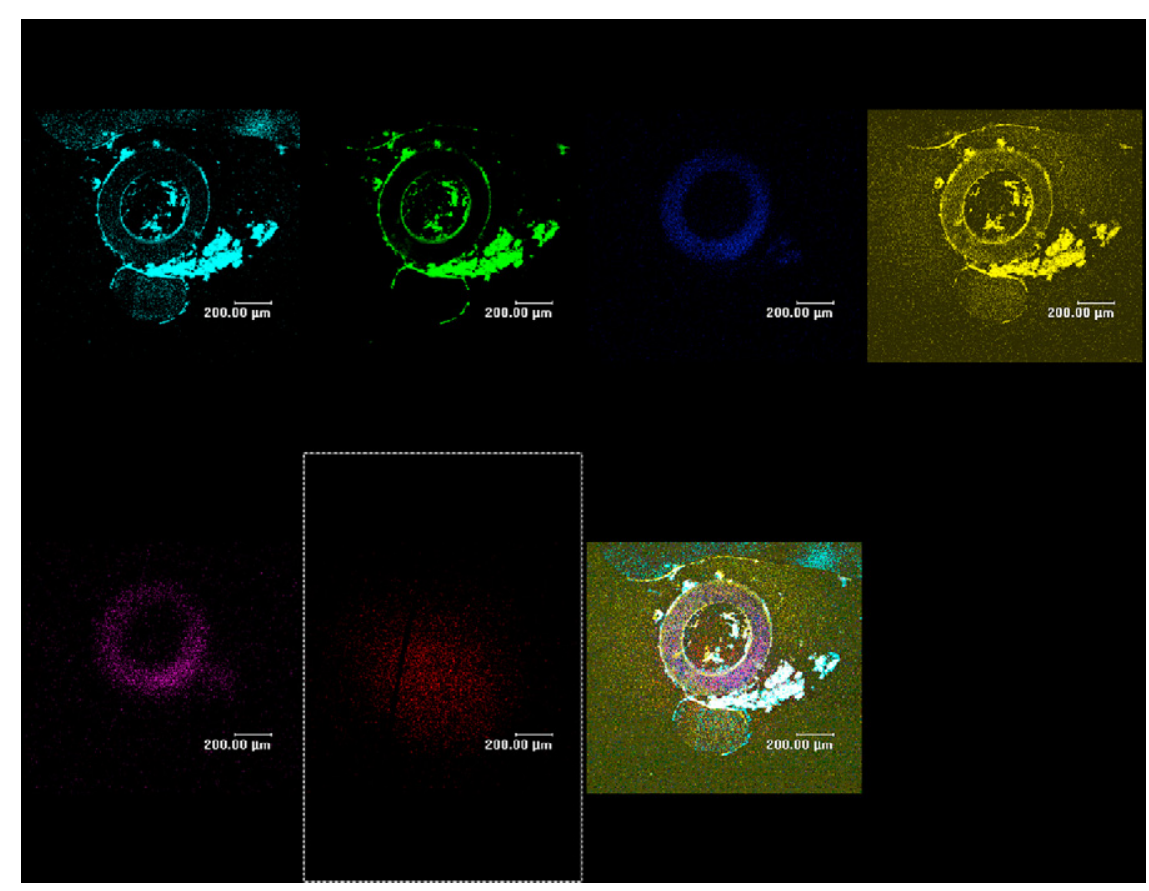

Fig. 2. The CLSM images for the fouling layers on single hollow-fibre membrane in AGMBR. Green: proteins; light blue: $\alpha$-polysaccharides; deep blue: $\beta$ polysaccharides; yellow: lipids; red: cells; pink: dead cells. Bottom and right: combined image. (For interpretation of the references to color in this figure legend, the reader is referred to the web version of the article.) 


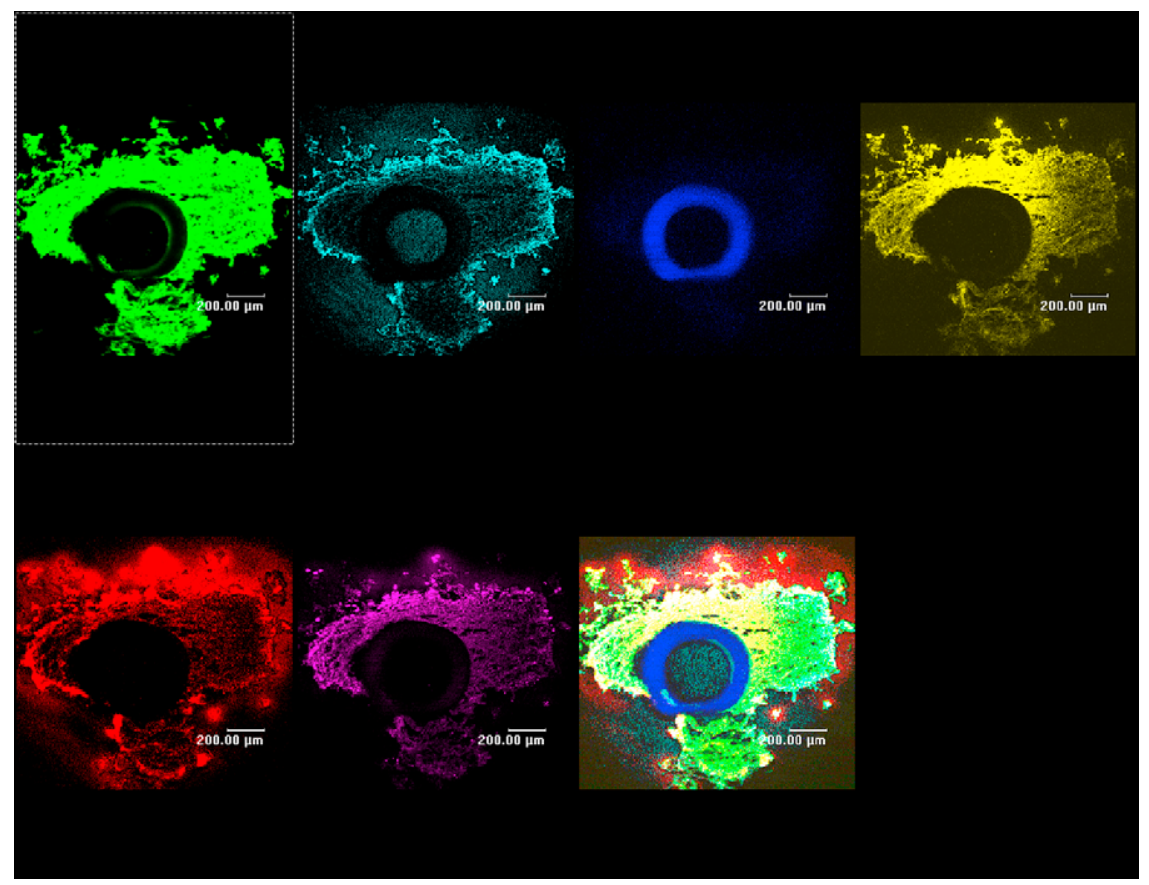

Fig. 3. The CLSM images for the fouling layers on single hollow-fibre membrane in SMBR. Green: proteins; light blue: $\alpha$-polysaccharides; deep blue: $\beta$ polysaccharides; yellow: lipids; red: cells; pink: dead cells. Bottom and right: combined image. (For interpretation of the references to color in this figure legend, the reader is referred to the web version of the article.)

\subsection{Fouling layers and irreversible fouling}

Experimental results revealed that the quantity of fouling layer on membrane does not necessarily correlate with the significance of irreversible fouling. The bulky fouling layer built up in SMBR yielded early TMP rise, but delayed irreversible fouling (Fig. 1). The slender fouling layer in AGMBR could not produce reversible fouling resistance, but could not prevent penetration of fine foulants into the membrane. The membrane "sludging" reduces effective membrane for filtration, but hinders easy clogging of internal pores by fines.

In both reactors, $\beta$-polysaccharides were little detected in the fouling layer. Adav et al. (2008) noted the accumulation of $\beta$-polysaccharides inside the aerobic granules to form its backbone supporting the cells. Apparently these integrants were not released to the suspension as membrane pollutants for AGMBR, hence were not detected in the fouling layer. Conversely, the lacking of $\beta$-polysaccharides in SMBR was not attributable to the screening action of bioaggregates from contacting the membrane. The $\beta$-polysaccharides hence likely were produced by the cells in aerobic granules but in the activated sludge.

Prevention of irreversible fouling is one of the main obstacles to practical use of the AGMBR.

\section{Conclusions}

The AGMBR and SMBR were tested with phenol-containing synthetic wastewater with TMP data probed over time. The SMBR has an early TMP rise, principally owing to the build-up of reversible fouling resistance which can be removed by backwashing. Irreversible fouling occurred afterwards, increased mildly over time. Conversely, the AGMBR exhibited a delayed TMP rise. However, once occurred, irreversible fouling dominated the resistance. Backwashing removed minimal irreversible fouling.

Fouling layer on hollow-fibre membrane in SMBR and AGMBR was directly observed for the first time using fluorescent staining technique. Fouling layers in both reactors presented a rather heterogeneous fouling layer, with that on SMBR much more redundant than that on AGMBR. The EPS in the AGMBR fouling layer was principally consisted of proteins, $\alpha$-polysaccharides, and lipids, with few $\beta$-polysaccharides or cells. In SMBR, large quantity of DNA was probed in the fouling layer. The redundancy of fouling layer does not correlate with the significance of irreversible fouling. Membrane sludging reduces effective membrane for filtration, but may assist preventing membrane clogging in an irreversible manner.

\section{References}

Adav, S. S. and D. J. Lee, "Single-Culture Aerobic Granules with Acinetobacter calcoaceticus," Appl. Microbiol. Biotechnol., 78, 551 (2007).

Adav, S. S., M. Y. Chen, D. J. Lee, and N. Q. Ren, "Degradation of Phenol by Acinetobactor Strain Isolated from Aerobic Granules," Chemosphere, 67, 1566 (2007a).

Adav, S. S., M. Y. Chen, D. J. Lee, and N. Q. Ren, "Degradation of Phenol by Aerobic Granules and Isolated Yeast Candida tropicalis," Biotechnol. Bioeng., 96, 844 (2007b).

Adav, S. S., D. J. Lee, and J. Y. Lai, "Effects of Aeration Intensity on Formation of Phenol-fed Aerobic Granules and Extracellular Polymeric Substances,' Appl. Microbiol. Biotechnol., 77, 175 (2007c).

Adav, S. S., D. J. Lee, and N. Q. Ren, "Biodegradation of Pyridine Using Aerobic Granules in the Presence of Phenol," Water Res., 41, 2903 (2007d). 
Adav, S. S., D. J. Lee, and J. H. Tay, "Activity and Structure of Stored Aerobic Granules," Environ. Technol., 28, 1227 (2007e).

Adav, S. S. and D. J. Lee, "Extraction of Extracellular Polymeric Substances from Aerobic Granule with Compact Interior Structure," J. Hazard. Mater., 154, 1120 (2008a).

Adav, S. S. and D. J. Lee, "Physiological Characterization and Interactions of Isolates in Phenol Degrading Aerobic Granules," Appl. Microbiol. Biotechnol., 78, 899 (2008b).

Adav, S. S., D. J. Lee, K. Y. Show, and J. H. Tay, "Aerobic Granular Sludge: Recent Advances," Biotechnol. Adv., 26, 411 (2008a).

Adav, S. S., D. J. Lee, and J. H. Tay, "Extracellular Polymeric Substances and Structural Stability of Aerobic Granule," Water Res., 42, 1644 (2008b).

Beun, J. J., A. Hendriks, M. C. M. van Loosdrecht, E. Morgenroth, P. A. Wilderer, and J. J. Heijnen, "Aerobic Granulation in a Sequencing Batch Reactor," Water Res., 33, 2283 (1999).

Chang, C. Y., C. Huang, J. R. Pan, and B. J. Wu, "Modification of Immunomagnetic Separation Procedures for Analysis of Cryptosporidium at Spiked Oocysts and Turbid Sample Conditions," J. Environ. Eng. Manage., 17, 333 (2007).

Chen, J. H., X. Hwang, and D. J. Lee, "Study on Bisphenol A Removal by a Membrane Bioreactor," Process Biochem., 43, 451 (2008).

Chiang, K. Y., H. J. Huang, and C. N. Chang, "Enhancement of Heavy Metal Stabilization by Different Amendments during Sewage Sludge Composting Process," J. Environ. Eng. Manage., 17, 249 (2007).

Cho, J., G. Amy, and J. Pellegrino, "Membrane Filtration of Natural Organic Matter: Internal Comparison of Rejection and Flux Decline Characteristics with Ultrafiltration and Nanofiltration Membranes," Water Res., 33, 2517 (1999).

Chu, S. D., T. C. Hwang, C. P. Chen, K. Y. Tang, and F. L. Lin, "Transfer of Plasmid Borne Antibiotic Resistant Determinants in Escherichia Coli Isolated from Kao-Ping River,” J. Environ. Eng. Manage., 17, 225 (2007).

De Kreuk, M. K., N. Kishida, and M. C. M. van Loosdrecht, "Aerobic Granular Sludge - State of the Art," Water Sci. Technol., 55, 75 (2007).

Heijnen, J. J. and M. C. M. van Loosdrecht, "Method for Acquiring Grainshaped Growth of a Microorganism in a Reactor," Euro. Patent EP 0826639 (1998).

Jarusutthirak, C., G. Amy, and J. P. Croue, "Fouling Characteristics of Wastewater Effluent Organic Matter (EfOM) Isolated on NF and UF Membranes," Desalination, 145, 247 (2002).

Jiang, H. L., J. H. Tay, and S. T. L. Tay, "Aggregation of Immobilized Activated Sludge Cells into Aerobically Grown Microbial Granules for the Aerobic Biodegradation of Phenol," Lett. Appl. Microbiol., 35, 439 (2002).

Jun, A., F. L. Yang, F. G. Meng, A. Peng, and W. Di, "Comparison of Membrane Fouling during Short-term Filtration of Aerobic Granular Sludge and Activated Sludge," J. Environ. Sci.-China, 19, 1281 (2007).

Lin, Y. M., Y. Liu, and J. H. Tay, "Development and Characteristics of Phosphorous-Accumulating Granules in Sequencing Batch Reactor," Appl. Microbiol. Biotechnol., 62, 430 (2003).

Liu, Y. and J. H. Tay, "State of the Art of Biogranulation Technology for Wastewater Treatment," Biotechnol. Adv., 22, 533 (2004).

Liu, W. D. and C. Y. Lee, "Practical Identification Analysis of Haldane Kinetic Parameters Describing Phenol Biodegradation in Batch Operations," $J$. Environ. Eng. Manage., 17, 71 (2007).
Moy, B. Y. P., J. H. Tay, S. K. Toh, Y. Liu, and S. T. L. Tay, "High Organic Loading Influences the Physical Characteristics of Aerobic Sludge Granules," Lett. Appl. Microbiol., 34, 407 (2002).

Ramesh, A., D. J. Lee, M. L. Wang, J. P. Hsu, R. S. Juang, K. J. Hwang, and J. C. Liu, "Biofouling in Membrane Bioreactor," Separ. Sci. Technol., 41, 1345 (2006).

Ramesh, A. D. J. Lee, and J. Y. Lai, “Membrane Biofouling by Extracellular Polymeric Substances or Soluble Microbial Products from Membrane Bioreactor Sludge," Appl. Microb. Biotechnol., 74, 699 (2007).

Rosenberger, S., H. Evenblij, S. te Poele, T. Wintgens, and C. Laabs, "The Importance of Liquid Phase Analyses to Understand Fouling in Membrane Assisted Activated Sludge Processes-Six Case Studies of Different European Research Groups," J. Membr. Sci., 263, 113 (2005).

Seo, G. T., S. W. Jan, S. H. Lee, and C. H. Yoon, "The Fouling Characterization and Control in the High Concentration PAC Membrane Bioreactor HCPACMBR," Water Sci. Technol., 51, 77 (2005).

Shi, H. P. and C. M. Lee, "Use of 31P NMR to Investigate Polyphosphate Accumulation in Brachymonas sp. P12 with Acetate as the Sole Carbon Source under Repeated Anoxic Batch Cultivation," J. Environ. Eng. Manage., 17, 319 (2007).

Smith, K. L., D. Di Gregorio, and R. M. Talcott., "The Use of Ultrafiltration Membrane for Activated Sludge Separation," Proc. 24th Annual Purdue Industrial Waste Conference, Purdue University, p. 1300 (1969).

Sridang, P. C., M. Heran, and A. Grasmick, "Influence of Module Configuration and Hydrodynamics in Water Clarification by Immersed Membrane Systems," Water Sci. Technol., 51, 135 (2005).

Tay, J. H., Q. S. Liu, and Y. Liu, "Microscopic Observation of Aerobic Granulation in Sequential Aerobic Sludge Blanket Reactor," J. Appl. Microbiol., 91, 168 (2001).

Tay, J. H., P. Yang, W. Q. Zhuang, S. T. L. Tay, and Z. H. Pan, "Reactor Performance and Membrane Filtration in Aerobic Granular Sludge Membrane Bioreactor," J. Membr. Sci., 304, 24 (2008).

Thanh, B. X., C. Visvanathan, M. M. Sperandio, and R. Ben Aim, "Fouling Characterization in Aerobic Granulation Cupled Baffled Membrane Separation Unit," J. Membr. Sci., 318, 334 (2008).

Wang, M. L. and B. L. Liu, "Synthesis of 2-mercaptobenzimidazole from the Reaction of $o$-Phenylene Diamine and Carbon Disulfide in the Presence of Potassium Hydroxide," J. Chin. Inst. Chem. Engrs., 38, 161 (2007).

Wang, J. F., X. Wang, Z. G. Zhao, and J. W. Li, "Organics and Nitrogen Removal and Sludge Stability in Aerobic Granular Sludge Membrane Bioreactor," Appl. Microbiol. Biotechnol., 79, 679 (2008).

Yamamoto, K., M. Hiasa, T. Mahmood, and T. Matsuo, "Direct Solid-Liquid Separation Using Hollow Fibre Membrane in an Activated Sludge Aeration Tank," Water Sci. Technol., 24, 43 (1989).

Yang, S. F., Y. Liu, and J. H. Tay, "A Novel Granular Sludge Sequencing Batch Reactor for Removal of Organic and Nitrogen from Wastewater," $J$. Biotechnol., 106, 77 (2003).

Yang, C. F. and C. M. Lee, "Biodegradation and Dechlorination of Pentachlorophenol with a Pentachlorophenol Degrading Bacterium Sphingomonas Chlorophenolica," J. Environ. Eng. Manage., 17, 157 (2007).

Yu, S. L. and R. Stanford, "Field Evaluation of a Stormwater Bioretention Filtration System,” J. Environ. Eng. Manage., 17, 63 (2007). 